\title{
Pleasurable and Intersubjectively Embodied Experiences of Electronic Dance Music
}

\author{
RAGNHILD TORVANGER SOLBERG[1] \\ Department of Popular Music, University of Agder \\ ALEXANDER REFSUM JENSENIUS \\ Department of Musicology, University of Oslo
}

\begin{abstract}
How do dancers engage with electronic dance music (EDM) when dancing? This paper reports on an empirical study of dancers' pleasurable engagement with three structural properties of EDM: (1) breakdown, (2) build-up, and (3) drop. Sixteen participants danced to a DJ mix in a club-like environment, and the group's bodily activity was recorded with an infrared, marker-based motion capture system. After they danced, the subjects filled out questionnaires about the pleasure they experienced and their relative desire to move while dancing. Subsequent analyses revealed associations between the group's quantity of motion and self-reported experiences of pleasure. Associations were also found between certain sonic features and dynamic changes in the dancers' movements. Pronounced changes occurred in the group's quantity of motion during the breakdown, build-up, and drop sections, suggesting a high level of synchronization between the group and the structural properties of the music. The questionnaire confirmed this intersubjective agreement: participants perceived the musical passages consistently and marked the build-up and drop as particularly pleasurable and motivational in terms of dancing. Self-reports demonstrated that the presence and activity of other participants were also important in the shaping of one's own experience, thus supporting the idea of clubbing as an intersubjectively embodied experience.
\end{abstract}

Submitted 2015 December 15; accepted 2016 June 13.

KEYWORDS: EDM, groups in motion, pleasure, intersubjectivity, motion capture

Music has the unique ability to temporally synchronize us, both physically and affectively. This can be seen in the way in which a group of people are able to move "together" to music and also share similar pleasurable experiences of dancing together. Such experiences are often to be found on night-club dance floors, a setting in which people dance both individually and collectively to loud and energetic music while spectacular visual effects light up the darkened space.

There are many studies of shared embodied experiences with electronic dance music (EDM) in club settings (Collin \& Godfrey, 1997; Fikentscher, 2000; Garcia, 2011; Jackson, 2004; Malbon, 1999; Reynolds, 1998; Rietveld, 1998; Thornton, 1995; St John, 2004). These studies, however, have tended to focus on sociological and cultural aspects, such as identity, social interaction, gender, and sexuality, and they have mainly used interpretive readings and ethnography as points of departure. As far as we know, there are no existing empirical investigations into how people move to EDM, what happens affectively in such settings, and how these body movements and affective engagements are related to sonic features in particular.

This paper reports on an experimental study of EDM dancers' experiences that was carried out in a controlled yet club-like environment. In it, we explore how the co-shaping of a shared experience happens in an EDM environment, as evidenced through motion capture data and subjective self-reports.

The general research question of the project is:

- How do people engage with EDM when dancing? 
This research question is approached from three different perspectives:

(1) Music: What is the role of the EDM track in the shaping of the club experience?

(2) Pleasure: What are the associations between how the participants move to the EDM track and their experience of pleasure?

(3) Intersubjectivity: In what ways can experiences with EDM be described as intersubjective?

An overall aim in the study has been to connect the affective and embodied aspects of the musical experience of EDM. This had some implications for the research design, in that we focused on creating a controlled experiment in a club-like setting that would hopefully evoke real life. In doing so, we ventured into fairly unexplored motion capture territory, since optical, marker-based motion capture systems have been little used in either complex group settings or real-life clubbing situations. The paper starts with a review of some relevant literature, followed by a presentation and discussion of the experiment and its results.

\section{BACKGROUND}

\section{Electronic Dance Music (EDM)}

EDM is produced electronically with the intention of making people dance (and keep dancing). The umbrella term EDM covers a large number of categories, such as house, techno, trance, and garage music, but most display the following musical characteristics:

- Repetitive and electronically produced rhythmic and melodic features

- A quantized rhythmic framework with a strong and energetic beat in $4 / 4$

- Bass drum kicks on every downbeat and hi-hat sounds on the offbeats, which may be referred to as the 'PoumTchak pattern' (Zeiner-Henriksen, 2010)

- An average tempo of 120-130 beats per minute

- A sequenced-based principle of adding, changing, or removing musical layers after two, four, eight, sixteen, or thirty-two bars

- Few harmonic shifts-most often progressions with two or four chords

To the untrained ear-or foot—EDM may appear repetitive and "static," but there are, in fact, clear structural conventions embedded in the tracks. Butler (2006) describes how an EDM track is based on structural and textural variations that produce changing intensity and energy in the music. We have been particularly interested in understanding more about how, what we refer to as the break routine, influences the dancing of people. The break routine usually consists of the following three elements:

(1) breakdown

(2) build-up

(3) drop

Dramaturgically, the break routine seeks to break down the dancers' engagement, then build it back up and ultimately generate a peak in the intensity of the dance experience.[2] There are numerous ways of creating such break routines, and producers and DJs have their own techniques. Musically, the breakdown represents the track's contrasting section, during which the texture becomes much sparser. In the build-up, the musical features are gradually reintroduced, alongside additional intensifying effects. Finally, the drop arrives, as the bass and bass drum — that is, the beat itself—are "dropped" back into the groove.

\section{Music-Related Movements}

There have been numerous studies of what might be called music-related body movement in recent years (Godøy \& Leman, 2010; Gritten \& King, 2006, 2011; Wanderley \& Battier, 2000), encompassing everything from performers' sound-producing actions to the sound-accompanying movements found in, for example, dancers. While there have been relatively few studies of movements related to EDM, more research has been 
done on how and why we synchronize our bodies to music in the first place (Chen, Penhune, \& Zatorre, 2009; Leman \& Naveda, 2010; Repp, 2005; Repp \& Su, 2013; Stupacher, Hove, Novembre, Schutz-Bosbach, \& Keller, 2013; Toiviainen, Luck, \& Thompson, 2010; Zentner, Eerola, \& Purves, 2010). There have also been studies on dancing and expressive sound-accompanying movements (Camurri, Lagerlof, \& Volpe, 2003; Camurri, Mazzarino, Ricchetti, Timmers, \& Volpe, 2003; Haga, 2008).

Bodily responses to musical sound occur at many different levels, ranging from basic beat-level synchronization to more indirect relationships between complex body movements and interpreted emotional content in the music (Leman, 2008). It has been found, for example, that people tend to move with larger, faster, and more fluid movements to "happy" music than to "sad" music (Burger, Saarikallio, Luck, Thompson, \& Toiviainen, 2013; Burger, Thompson, Luck, Saarikallio, \& Toiviainen, 2013; Camurri, Lagerlof et al., 2003; Dahl \& Friberg, 2003; Van Dyck, Maes, Hargreaves, Lesaffre, \& Leman, 2013). Furthermore, our movements become faster, more regular, and jerkier with a steady beat (Burger, Saarikallio et al., 2013; Burger, Thompson, et al., 2013). Because EDM is a musical style with a very strong beat, in addition to a high level of energy, we expect that our study will support these findings. Furthermore, we anticipate that participants will change their movements in relation to the different passages of the break routine, and that they will move more after the reintroduction of the bass drum in the drop moment. This prediction is based on the research of Van Dyck and colleagues (2013), who found that the presence of the bass drum influences and improves our amount of body movement.

It has been shown that people prefer to move to music at a tempo between 120 and 125 beats per minute (Moelants, 2002). This is closely related to the finding of a $2 \mathrm{~Hz}$ base frequency in everyday bodily activity (MacDougall \& Moore, 2005). In EDM, the most frequently used tempo is $128 \mathrm{bpm}$-in other words, suitable for somewhat more energetic and excited dancing (Moelants, 2008).

\section{Pleasure}

There are several competing hypotheses as to why dancing to EDM may shape pleasurable experiences, and in what follows we will focus on two: peak sensations and continuous embodied sensations.

The peak-sensation hypothesis has traditionally been the most investigated, generally through selfreports, physiological responses, and brain imaging. Some studies have found that music is associated with the release of dopamine via the brain's reward system, in the same way that food, sex, and money are (Blood \& Zatorre, 2001; Gebauer, Kringelbach, Vuust, Cohen, \& Stewart, 2012; Salimpoor, Benovoy, Larcher, Dagher, \& Zatorre, 2011). Perhaps, then, we experience music as pleasurable when our musical expectations are either fulfilled or violated, and dopamine release may occur in anticipation of this reward (Gebauer et al., 2012; Salimpoor et al., 2011). Related sensations are often described as chills, goose bumps, or shivers, and they seem to correspond to sudden and unexpected changes or gradual expansions in the dynamics, texture, structure, tempo, and volume of the musical sound (see, for example, Blood \& Zatorre, 2001; Gomez \& Danuser, 2007; Grewe, Kopiez, \& Altenmüller, 2009; Guhn, Hamm, \& Zentner, 2007; Juslin \& Västfjäll, 2008; Panksepp, 1995; Rickard, 2004). Most studies of peak pleasurable sensation have focused on sedentary listening, however, and these findings may not directly relate to EDM, which features dancing as an important element.[3] We have therefore sought to develop an ecologically valid research design that makes it possible to measure peak pleasurable sensations while moving.

A second model for how musical pleasure is created is the perception-production loop that occurs when we move to a regular auditory pulse (Overy \& Molnar-Szakacs, 2009). Recent studies have shifted toward a more embodied approach to continuous musical pleasure and emphasized its close relation to the desire to move (Grewe et al., 2009; Janata, Tomic, \& Haberman, 2012; Witek, 2013; Witek, Clarke, Wallentin, Kringelbach, \& Vuust, 2014). Janata and colleagues (2012) found a correspondence between movement and enjoyment and propose that movement induction is closely connected to positive affects such as pleasure. This theory introduces a dynamic understanding of pleasure-that is, that the experience of pleasure and the desire to move happen simultaneously, and that they reinforce one another. Relatedly, people can therefore experience continuous pleasure when moving to music over a longer period of time (Witek et al., 2014). This happens even when the structural properties of the music in question are highly established and readily anticipated, as is the case with most groove-based music. Here, then, the reward is in the fulfillment of our desire to move, not merely in the dopamine release related to our musical expectations. Interestingly, however, dopamine release is central to both our experience of pleasure and our motor control, perhaps providing evidence of the close connection between pleasure and the desire to move (Keitz, MartinSoelch, \& Leenders, 2003). 
The continuous-embodied-sensation model focuses on a holistic approach to pleasure and strengthens the coupling between affective experience and body movement. It further supports one of this article's main claims - that body movement directly expresses our affective involvement with music. Assuming a close link between affective arousal and changes in body movement, we can therefore hypothesize that body movements indicate the level of intensity of peoples' affective engagement with the music.

\section{Intersubjectively Embodied Experience}

We have decided to use the term "intersubjectively embodied experience" to describe dancing in an EDM club setting. In the musicological literature, several terms are currently applied to shared musical experiences: interpersonal experiences, co-subjectivity, collective experience, group interaction, group cohesion, and intersubjectivity. We find the latter to be the most precise for our purposes, as it refers to something that is existing, occurring, or shared between two or more conscious minds ("Intersubjective," 2015a; "Intersubjective," 2015b), but also something that "presumes interpersonal dialogue and the collaborative production of meaning and cognition. Intersubjectivity [...] involves a collaborative version of reflexivity" (DeNora, 2000, p. 153). The inclusion of "embodied" in our term is meant to underscore the role of the body in the club setting, and the way in which dancers shape a pleasurable experience when they together engage with the musical sound presented to them.

The term "intersubjectively embodied experience" also points to the conscious and collaborative aspects of an experience and reflects our claim that dancers have a shared embodied knowledge of how to perceive the musical features of EDM. There are several studies that may support this idea. First, it has been shown that participating in a social context encourages us to move more intensively than when we are alone (De Bruyn, Leman, Moelants, \& Demey, 2009; McNeill, 1995), and that our ability to synchronize also improves in a group setting. Such synchronized movements may contribute to a "fellow feeling"-that is, a sensation of belonging and community (McNeill, 1995) or, as Godøy and Leman (2010) postulate: "When one's movement is in time with the movements of others, this may lead to very intense experiences of unity or social bonding. In this sense, the meaning of music is not something external to the movement itself, but something that is tightly connected to it” (2010, p. 10). In shared experiences of music, rhythm is a key feature that coordinates our actions and further shapes a shared and heightened sensation of what is happening (Becker, 2004; Blacking, 1992; Clayton, Sager, \& Will, 2004; Keil \& Feld, 2005; Lomax, 1982).

Affect is another key term when it comes to explaining the process of social bonding. Music-related movement may here be seen as an efficient conveyor of our feelings about the music in question. Likewise, empathy and imitation stand out as important concepts in our understanding of intense and pleasurable musical group behavior. Empathy relates to emotional identification and feelings of social connectedness in a group (Berthoz \& Jorland, 2004). Imitation may be seen in how people imitate sonic features, such as following the contour of a melody, or imitate sound-producing actions, such as playing "air instruments.” Imitation can also occur in groups, in which people standing close to each other in a dance setting shape a group articulation (Leman, 2008, p. 111). Such behavior may be explained by mirror neurons engaging our motor system at a pre-conscious perceptual level, meaning that when we observe other people's movements, it activates the same neurons as if we performed the action ourselves (Molnar-Szakacs \& Overy, 2009).

Based on current knowledge, as reviewed above, we expect to find a relationship between peak pleasurable experiences and specific structural properties of EDM, and to find that this is related to people's movement. We expect that the movements will follow the same dynamic development as physiological responses to large-scale structural peaks in the music, due to the close relationship between affective and bodily engagement. Lastly, we predict that dancers have an intersubjectively embodied understanding of how to perceive the musical features of EDM.

\section{METHOD}

To investigate intersubjectively embodied experiences with EDM, we created a club-like atmosphere in a motion capture lab. A group of people were invited to dance together to a DJ mix in this setting and filled out a questionnaire afterwards about their dance experience. 


\section{Participants}

Sixteen participants $(f=11, m=5)$ aged from 22 to 54 years old $(M=30.3$ years, $S D=8.6)$ took part in the study. Of these, 11 had formal musical training and 3 had informal musical training. All of the subjects adhered to the premises of the study: (i) familiarity with EDM, and (ii) enjoyment in dancing with others. The majority of the participants (75\%) responded that they dance quite often to music, both at clubs and at home.

Some of the recruited participants invited friends to join, so the group consisted of people who were both familiar and unfamiliar to each other, further evoking an actual club setting. The participants were recruited through university courses and social media channels. Ethical approval was granted from the Norwegian Social Science Data Service, and informed consent was obtained from everyone. The participants did not receive any reward or monetary compensation. To control for the effect of alcohol or other drugs, we performed the experiment in the evening in a controlled lab setting. None of the participants appeared to be under the influence of any intoxicating substances before, during, or after the dance session. This was further confirmed by the questionnaire, in which several of the participants commented that alcohol intake might have changed their experience in a real club setting.

\section{Materials}

\section{MUSIC}

The musical material used in the experiment was a pre-recorded DJ mix lasting for a little more than 14 minutes, played back loudly through an immersive 42-channel surround-sound system. The sound track was mixed by the first author and consisted of the following real dance music excerpts in Table 1, all of which are representative of house tracks used in EDM clubs in recent years:

Table 1. Overview of the four EDM tracks used in the dance experiment.

\begin{tabular}{|c|c|c|c|c|}
\hline DJ Mix & Structure & Function & Tempo & Duration \\
\hline Intro of Track 1 & & & & 00:00-00:31 \\
\hline $\begin{array}{l}\text { Track 1. “Joyride” (Rhode \& } \\
\text { Brown. Schegg. 2013) }\end{array}$ & Flat & Start-up track & 122 bpm & $00: 31-01: 50$ \\
\hline Transition & & & & $01: 50-02: 53$ \\
\hline $\begin{array}{l}\text { Track 2. "Ladykiller (Original } \\
\text { Mix)" (Vanilla Ace, 2014) }\end{array}$ & $\begin{array}{l}\text { With } \\
\text { routine }\end{array}$ & $\begin{array}{l}\text { Breakdown, } \\
\text { build-up, drop }\end{array}$ & 124 bpm & $02: 53-07: 04$ \\
\hline Transition & & & & $07: 04-8: 22$ \\
\hline $\begin{array}{l}\text { Track 3. “Unlock Down (Original } \\
\text { Mix)” (NUAGE, 2014) }\end{array}$ & Flat & Control track & $126 \mathrm{bpm}$ & $08: 22-10: 22$ \\
\hline Transition & & & & $10: 22-11: 24$ \\
\hline $\begin{array}{l}\text { Track 4. "Icarus (Extended Mix)” } \\
\text { (Madeon, 2012) }\end{array}$ & $\begin{array}{l}\text { With } \\
\text { routine }\end{array}$ & $\begin{array}{l}\text { Breakdown, } \\
\text { build-up, drop }\end{array}$ & 127 bpm & $11: 24-13: 12$ \\
\hline Outro of Track 4 & & & & $13: 12-14: 15$ \\
\hline
\end{tabular}

We decided that approximately 15 minutes would be an appropriate length for the dance session; the participants would become sufficiently familiar with the situation yet not lose interest or focus. To simulate an actual club setting, the music was played back as one continuous mix, in which the different tracks were beat-matched and mixed into one another. Thus the tracks varied in duration and structure, and we included a gradual tempo increase throughout the mix to make the transitions between the tracks as natural as possible. Tracks 2 and 4 comprised the break routine, while tracks 1 and 3 served as start-up and control tracks with little structural development. The questionnaire showed that most of the participants were not familiar with any of the tracks.

\section{QUESTIONNAIRE}

A web-based questionnaire was sent to the participants following the recording session and completed over the next few days. In it the participants were asked to rate the music tracks used in the dance study according to pleasure and familiarity, and they were also asked to describe any particular musical characteristics 
associated with their experienced pleasure. The four tracks from the DJ mix were embedded as audio files in the questionnaire to jog the participants' memories, and they were encouraged to use headphones while listening to the excerpts. The questionnaire also asked about demographic information such as education, formal and informal musical training, and music listening and dancing habits. 15 of the 16 participants completed the questionnaire.

\section{Apparatus}

The dancing of the participants was tracked and recorded using an infrared, marker-based motion capture system from Qualisys (Oqus 300). Each participant was equipped with two small non-obtrusive reflective markers: one marker was positioned on top of the head to pick up the overall movement of the body, while the other was attached to the wrist of the dominant hand to track the extremities of the body. Thus a total of 32 reflective markers were captured, at a frame rate of $100 \mathrm{~Hz}$.

An effort went into transforming the motion capture lab into a setting that resembled a club. For example, the main lights in the room were switched off, and five rotating and color-changing light effects machines were installed to move in synchronization to the beat of the music. The pre-recorded DJ mix was played back at a loud volume using a Max/MSP patch on the surround-sound system, which consisted of 42 Genelec 8020B speakers arranged in a 3D setup.
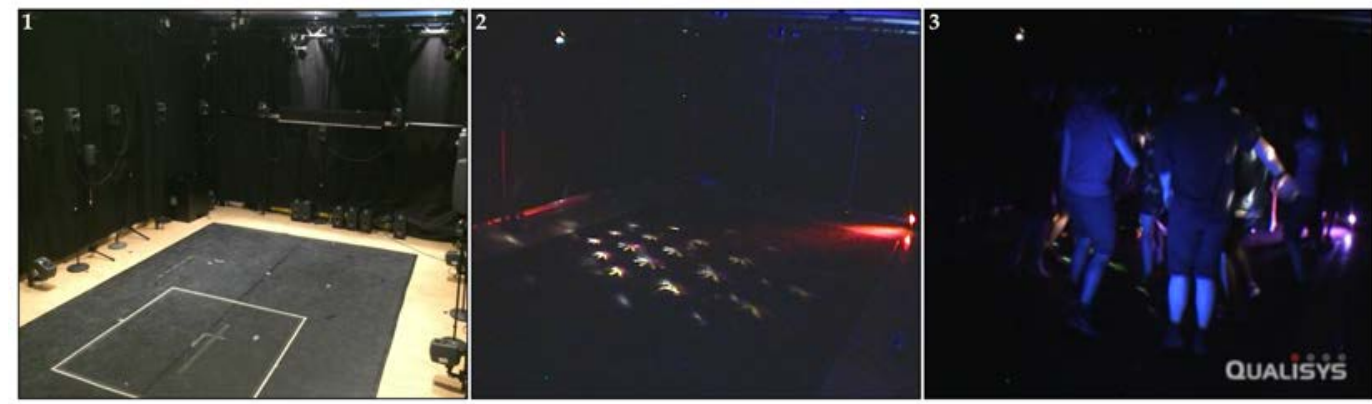

Fig. 1. The motion capture lab (1) before light adjustments, (2) after light adjustments, and (3) during the dance session.

\section{Procedure}

All 16 participants were recorded together in a dance session that lasted around 15 minutes. The participants were instructed to dance as they would have done in an actual club setting. They were further instructed to remain within the capture area, which was covered with a black carpet that measured approximately 5 by 3.5 meters (see Figure 1).

As mentioned previously, ecological validity was our main concern in the design of the experiment's setting. The experiment was carried out in the evening on a warm summer day using real (and loud) dance music. We tried to make the whole experience feel as natural as possible, even though the participants had to give their consent and be equipped with markers when they entered the space. Because they were restricted to a small dance space, they had to dance relatively close to one another, just as they would in an actual club setting. The participants reported that they found the experiment enjoyable and fun.

\section{RESULTS AND DISCUSSION}

The overall results of the analyses indicate correspondences between the participants' quantity of motion, their self-reported experience of pleasure, and the structural conventions in the music. We will consider the associations between body movements and musical features before exploring the associations between affective engagement and musical features. 


\section{Associations between Body Movements and Musical Features}

In the analysis of the motion capture data, we focused mainly on the global movement of the whole group with respect to specific musical features. This was a pragmatic solution, as it turned out to be difficult to track individual subjects over time due to marker occlusion. The participants danced very close together, many of them moved quite a lot, and many of them also raised their arms during the recordings. This made it difficult to satisfactorily identify individual markers over the entire recording, since there are so many individual motion trajectories in the dataset. Marker-based motion capture systems like ours are mainly used to track individual people via multiple markers, and in these cases it is fairly straightforward to resolve marker occlusion problems by gap-filling trajectories that are close in time and space. In our current dataset, however, there were only two markers per person. Since the participants were dancing so close together and moving in all directions, it was not possible to use a proximity-based gap-filling technique.

Even though there were many broken motion trajectories in the dataset, the overall tracking percentage was satisfactory, so we decided to focus on the general movement of the group for this analysis. No gap filling or smoothing was done with the Qualisys Track Manager; the motion trajectories were exported to C3D files and imported in Matlab using the MoCap Toolbox (Burger \& Toiviainen, 2015). There the global quantity of motion (QoM) of each trajectory was calculated as the sum of the cumulative distance traveled for each marker in all directions (XYZ) divided by time, or, more precisely,

$$
Q o M_{\text {trajectory }}=\frac{1}{T} \sum_{n=2}^{N}\|\boldsymbol{p}(n)-\boldsymbol{p}(n-1)\|
$$

where $\boldsymbol{p}$ is the XYZ position vector of a marker, $N$ is the total number of samples, and $T$ is the total duration of the recording. We calculated the global QoM by summing the QoM of all trajectories and normalizing the value by the number of recorded markers $(P)$ :

$$
Q o M=\frac{1}{P} \sum_{p=1}^{P} Q o M_{\text {trajectory }}(p)
$$

This gives a global QoM that indicates the average movement activity of the group, measured in millimeters per second $(\mathrm{mm} / \mathrm{s})$.

The plots in Figure 2 show how the group moved along with the four different tracks, with both the raw QoM data (grey) and the data smoothed with a 10-second Savitzky-Golay filter (black).

The figure also presents an amplitude plot of the audio track, including a filtered root-mean-square (RMS) plot (10-second Savitzky-Golay filter) for reference. We can see from Figure 2 that the group's mean QoM is relatively stable throughout the session, with an average value of $257 \mathrm{~mm} / \mathrm{s}$ for the entire recording and $286 \mathrm{~mm} / \mathrm{s}$ for the four main segments. There are, however, some interesting moments in the recording, most notably during tracks 2 and 4 . Both of these tracks have break routines, and in both instances the plots show a sudden and large decrease followed by an increase in QoM after the drop. More gradual changes in the QoM of the dancers occur in the transitions between the tracks, which follow the same gradual dynamic changes in the music, due to the tracks being mixed into one another.

Looking more closely at the break routines, it is possible to see differences between the tracks, including the break routine and control tracks. It is clear that the change is largest for track 4 ("Icarus"), which was also the track that the participants rated as "most pleasurable." This led us to examine this particular break in more detail. 

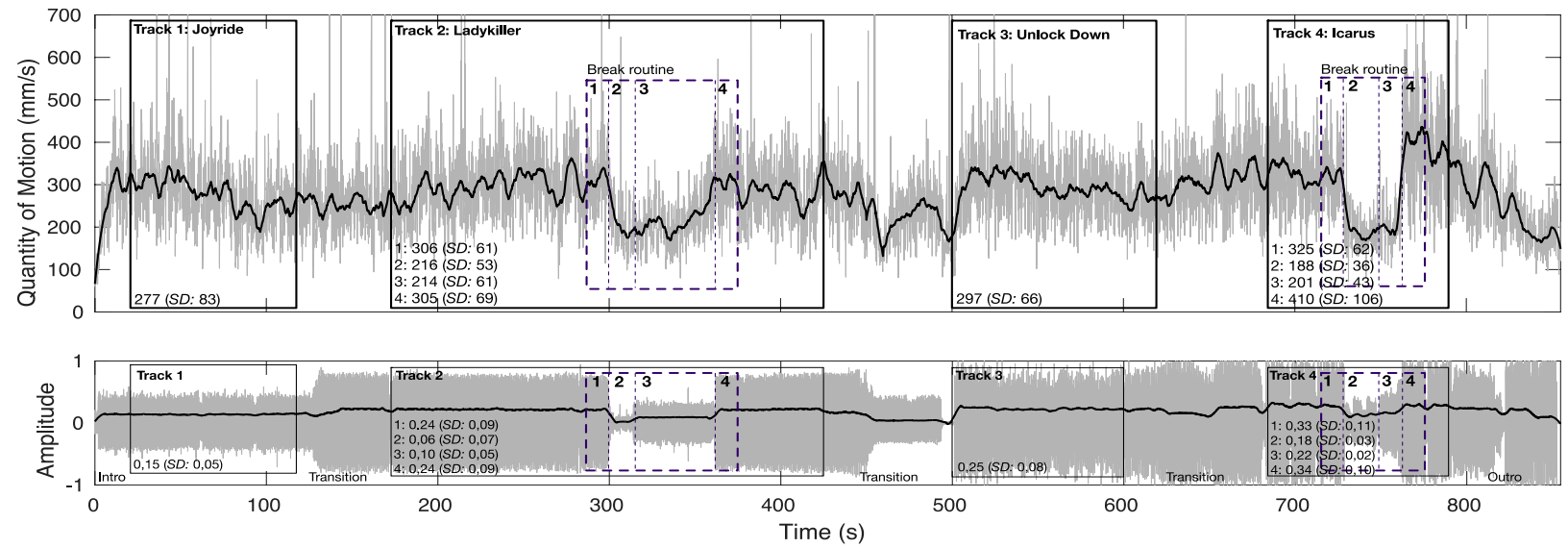

Fig. 2. Top: Plots of the raw (grey) and filtered (black) quantity of motion (QoM) for all subjects for the full dance session. Mean QoM values for the main segments of tracks 1 and 3 are included, in addition to the break routine of tracks 2 and 4: (1) pre-breakdown, (2) breakdown, (3) build-up, and (4) post-drop. Bottom: Plots of amplitude (grey) and filtered RMS (black) of the audio track. The black squares mark the main segment of each track, while the stippled squares highlight the two break routines that occur during the DJ mix. Mean values for the audio of the main segments of tracks 1 and 3 are included, in addition to the break routine of tracks 2 and 4: (1) pre-breakdown, (2) breakdown, (3) build-up, and (4) post-drop.[4]

As Figure 2 shows, both break routines (tracks 2 and 4) have an obvious effect on the dancers in comparison to the minimal structural development in the control tracks. But why does "Icarus" make a stronger bodily impact on the group than "Ladykiller"? We propose that this relates to the specific production techniques and sonic qualities of the musical passages of Icarus. The break routine of "Ladykiller" lasts longer than that of "Icarus" but does not feature the same contrasting breakdown passage. "Ladykiller" keeps the rhythmic feel throughout the break routine, and the main groove's bass line is present more or less all the time. The sonic build-up effect of "Ladykiller" mostly relies on a long, gradual opening of a low-pass filter, while the "Icarus" build-up is based on several intensifying musical features that are described in more detail below. This leads us to suggest that the arrival of the "Icarus" drop is experienced as more powerful and more pleasurable than the drop of "Ladykiller," because it is more intensely built up and starts out with a breakdown that contrasts the main groove.

Sonically, a number of changes occur in the "Icarus" excerpt:

- The main groove has a strong rhythmic focus with a rich texture. It can be described as a collage-based groove made by layering many short and rhythmic samples, creating a "sound wall" with an overall "punchy" and "bouncy" musical character.

- The breakdown passage (12:09) is characterized by the removal of several of the rhythmic and percussive features of the main groove. This reduces the track to only a few sonic features, which results in a "thinner" texture (as seen in Figures 3 and 4). The bass drum and other percussive features are replaced with a simple bass line and a set of sustained-string synth pads. In this way the breakdown contrasts with the rich and rhythmic main groove. It focuses on harmonic features, with no obvious pulse except through one of the synth's delay effects.

- The build-up (12:28) to the drop begins with claps on the second and fourth beats. A few main groove layers, such as a staccato melodic structure, gradually re-enter the soundscape alongside a slow increase in volume. The most noticeable features here relate to the textural changes: sounds and sound effects are pitched higher and higher-often referred to as uplifters - shifting the focus toward the higher frequency spectrum. A further intensifying feature is the $16^{\text {th }}$ note drum roll, which is gradually mixed louder in the soundscape. The drum roll culminates in a brief rhythmic switch consisting of a syncopated five-on-four polyrhythmic figure (represented in Figure 4) that sonically marks the arrival of the drop.

- The drop (12:42) marks the culmination of the track with a downward bass slide. The bass and bass drum are returned to the groove, along with the rest of the main groove layers. The PoumTchak pattern is fully reintroduced, and the track reasserts its rhythmic and percussive framework. 


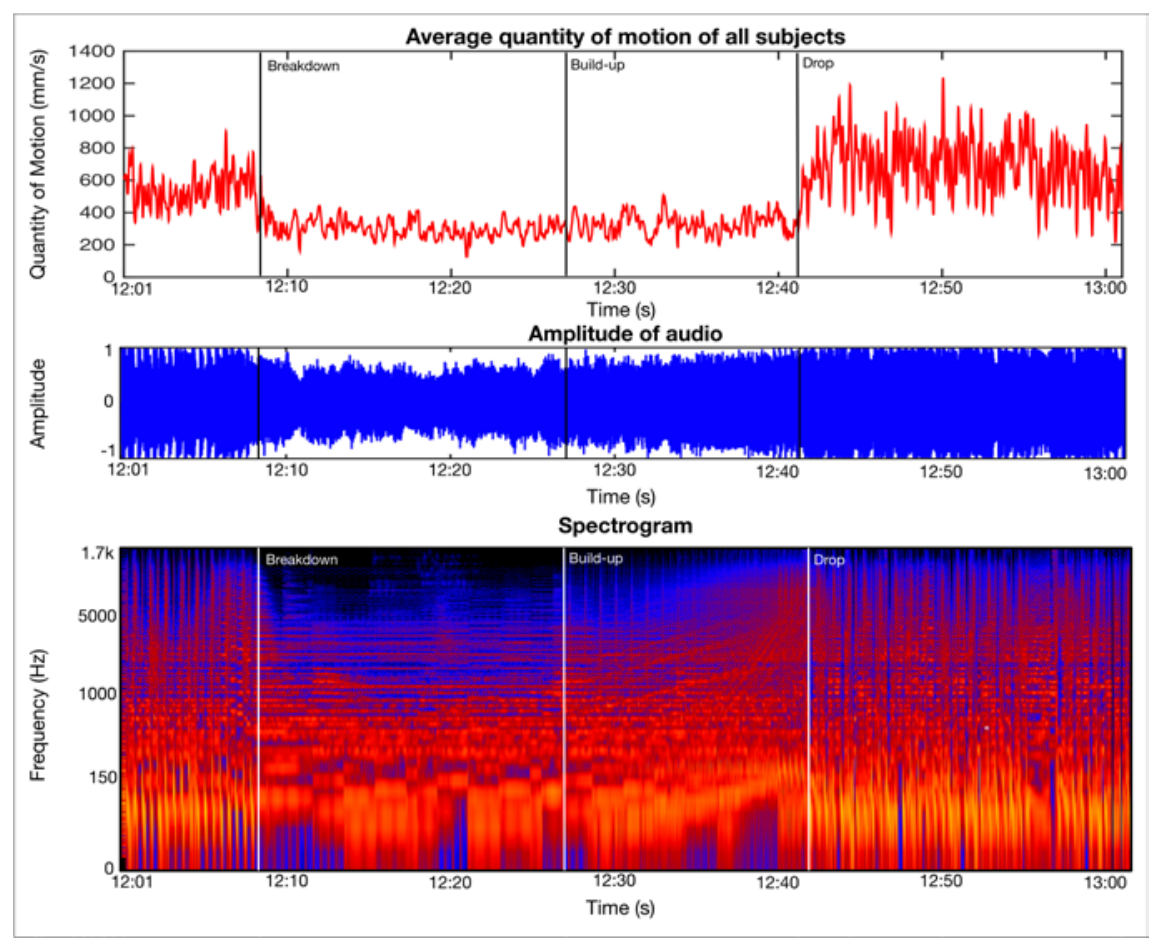

Fig. 3. Plots of the quantity of motion for all subjects, and the amplitude and log spectrogram of the sound of the break routine of "Icarus," consisting of breakdown, build-up, and drop. In the original track, the breakdown begins at 02:02 and the build-up at 02:21, while the drop occurs at 02:36.

The plots demonstrate a considerable decrease in the group's activity level when the breakdown sets in, along with a pronounced increase at the moment of the drop. It is interesting to see that the average QoM after the drop in "Icarus" is higher than the average QoM before the breakdown and build-up occurred. This indicates that these passages "energize" the group and its dancing. A qualitative analysis of the video recording of the session reveals that the quality of the dance movement also changes: the group moves with smaller, fewer, more fluid movements in the breakdown, as opposed to the drop, when the movements become larger, more pronounced, and more synchronized with the beat. Our results here support the idea that the dynamic level of the bass drum has a pronounced effect on people's bodily behavior when dancing together in groups (Van Dyck, Moelants et al., 2013).

In the control track ("Unlock Down") we can trace a different tendency in the group’s QoM. This track has little structural development, with few dynamic and textural changes. This track's core groove consists of two repetitive synth elements with a bass line that follows the syncopated synth chords. The rhythmic foundation is a PoumTchak pattern (Zeiner-Henriksen, 2010), with a clap cluster and some small variations in the hi-hat. As seen in Figure 5, the group's QoM follows this pattern steadily, with just a slight decrease in QoM throughout the excerpt. 

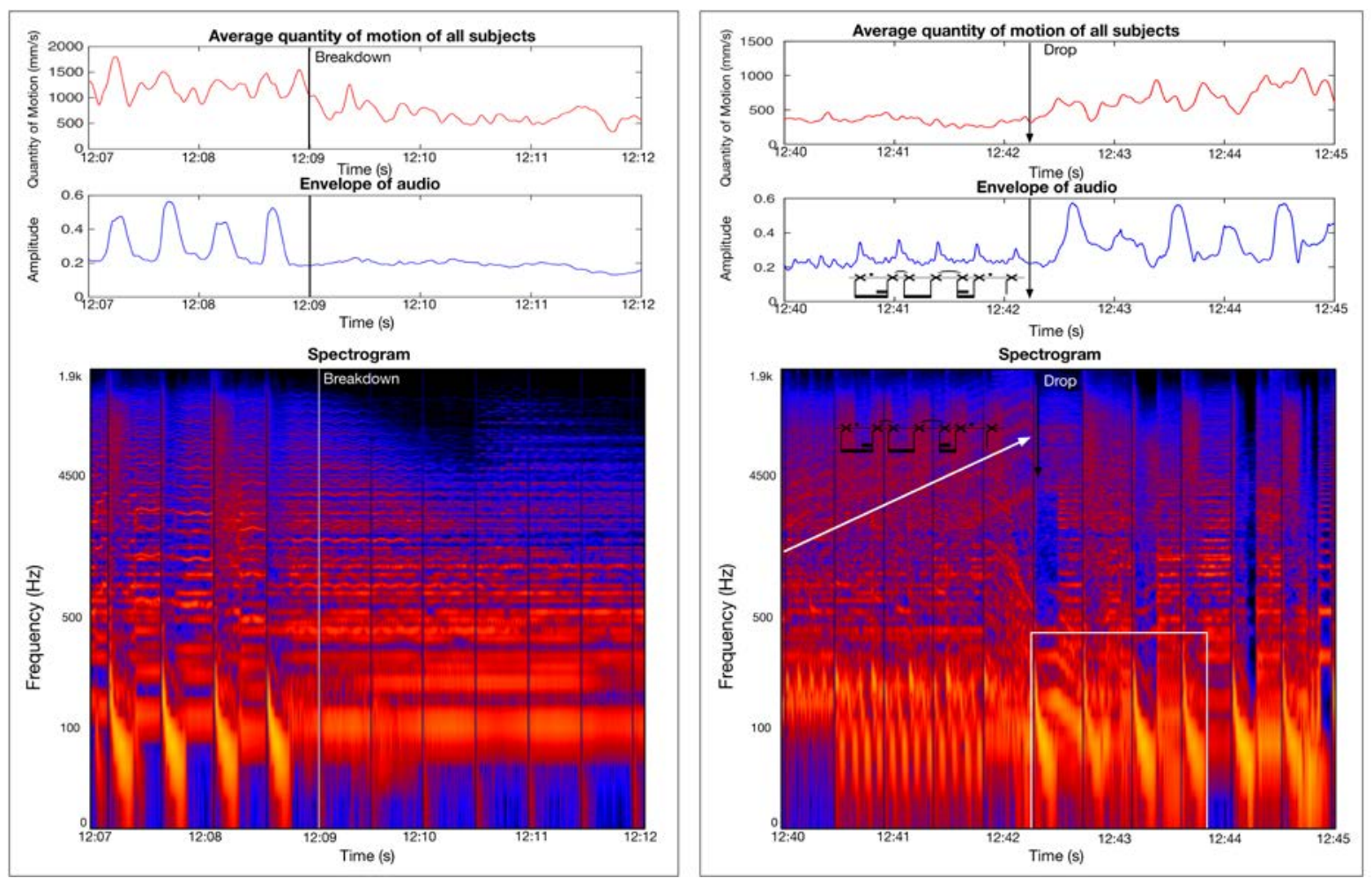

Fig 4. Left: Close-up plots of the QoM for all subjects, and the amplitude and log spectrogram of the sound of the breakdown of "Icarus." Right: Close-up plots of the QoM for all subjects, and the amplitude and log spectrogram of the sound of the drop of "Icarus." The white arrow indicates the uplifters, while the square marks the return of the four-to-the-floor bass drum. In the original track, the breakdown begins at 02:02 and the drop at 02:36. 


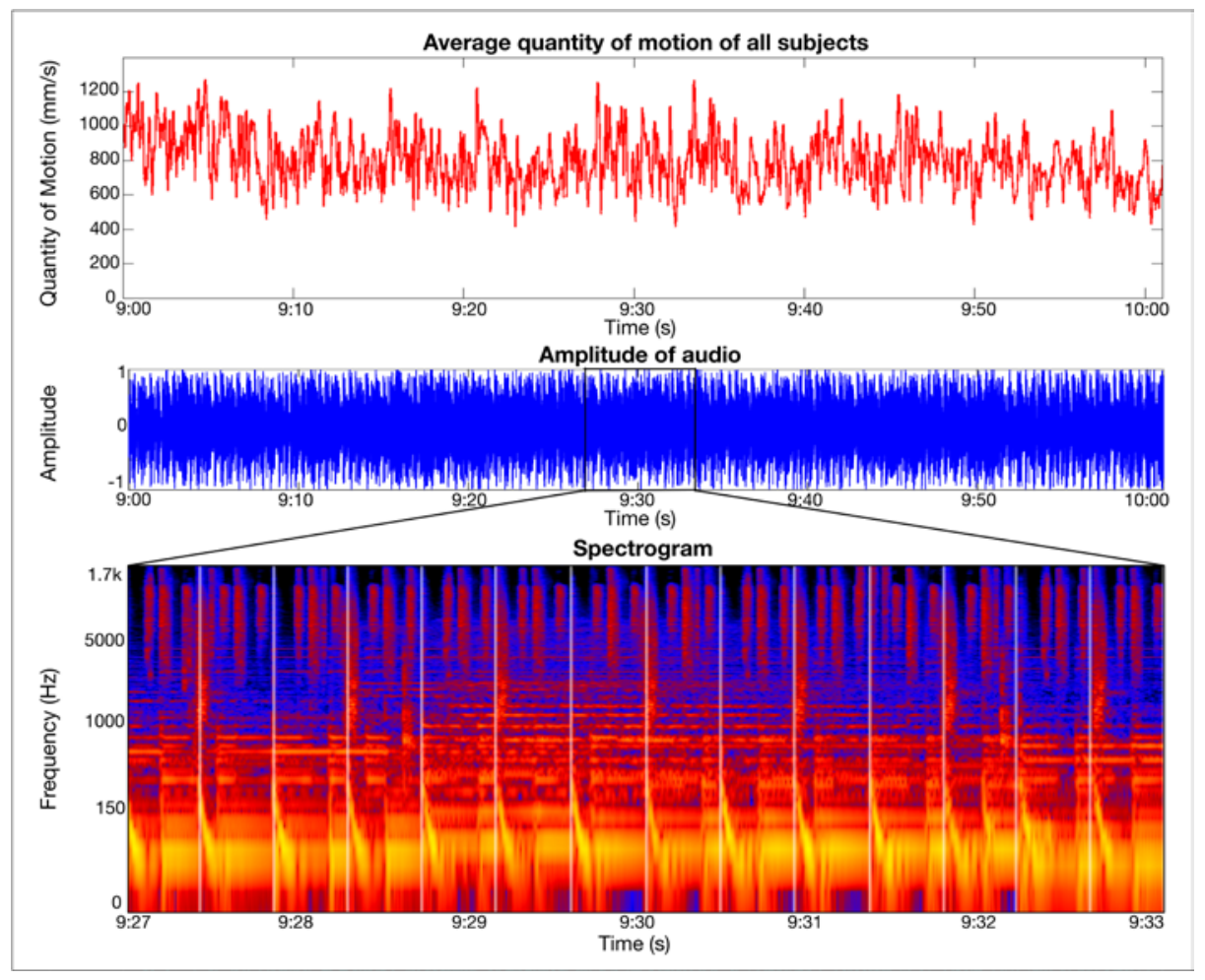

Fig. 5. Plots of the quantity of motion for all subjects, and the amplitude graph and log spectrogram of the sound of "Unlock Down."

\section{Associations between Affective Engagement and Musical Features}

The analysis of the questionnaires shows that the two tracks with the break routine were rated as more pleasurable than the tracks with a flat structural development. The pleasure ratings for all four tracks are summarized in Figure 6. Most of the participants (61\%) rated "Icarus" as "very pleasurable." "Ladykiller" was rated as "quite" to "very pleasurable" by $69 \%$ of the participants while "Icarus" is rated the same by $78 \%$ of the group. The control tracks did not score as high in the same pleasure categories_-"Joyride" (53\%) and "Unlock Down" (46\%). None of the participants found "Icarus" or "Ladykiller" to be "not pleasurable," and only a small percentage found "Unlock Down" (8\%) and "Joyride" (8\%) to be "not pleasurable."

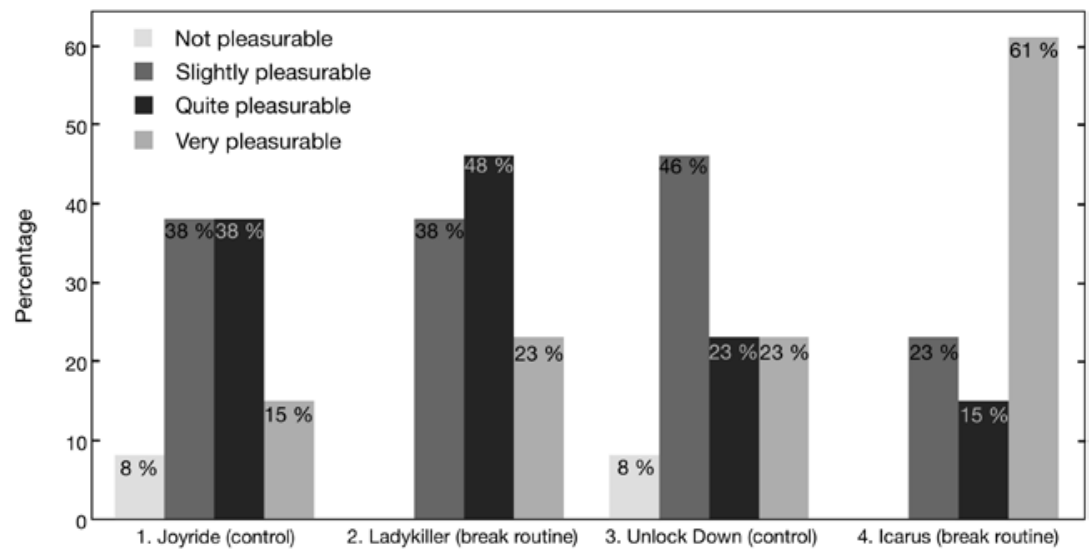

Fig. 6. Pleasure ratings of the four tracks used in the dance study. 
When asked about the tracks' danceability, the majority of the participants (81\%) reported a desire to dance "often" or "all the time” during the session (Table 3).

Table 3. Distribution of the participants' answer to the question "How often during the experiment did you experience a desire of your own to move or dance to the music?”

\begin{tabular}{|c|c|}
\hline Response alternative & Percentage \\
\hline Never & 0 \\
\hline A few times & 12.5 \\
\hline Often & 37.5 \\
\hline All the time & 43.8 \\
\hline Missing & 6.3 \\
\hline Total & 100 \\
\hline
\end{tabular}

The participants were also asked to freely describe which musical features made them:

i) experience a desire to dance

ii) experience an intense desire to dance

The replies to this free-text question could be sorted into two broad categories of musical features:

i) rhythmic drive and strong beat

ii) dynamic changes or structural properties

By cross-referencing these two questions, we found that the participants experienced a general desire to move based on the rhythmic drive and strong, regular beat of the music, while the intense desire to dance happened when an increase in texture and dynamics occurred, as in the build-up and drop. One of the participants described it as follows:

"When the music did a pronounced dynamic jerk, the wish to dance became extra strong."

Another person wrote:

“Especially after build-ups, I had a desire to dance."

A third person emphasized the anticipation of the drop as an important factor in the shaping of an intense dancing desire:

"This [an intense desire to move] happened when the track built towards a clear drop. I did, however, enjoy the building towards the drop more than the drop itself. It also gave me energy when I felt I knew the drop would come."

The questionnaire also revealed that the co-presence of others shapes the musical experience. The QoM measures indicate that the overall movement of a group of people changes consistently over time. Nonetheless, the qualitative evidence further indicates that the group has a shared musical understanding by revealing the importance of others being present and together experiencing the same musical passages. Participants reported positively about dancing with others, and $85 \%$ found the setting more authentic, fun, and natural because of the presence of others. One of the participants describes it as follows:

"I remember feeling the mood of the other participants shift-some audibly hollered and got excited by the reappearance of the bass, which was such a powerful moment, (...) that encouraged me to get more into it." 
Another reflects on being a stranger in the group:

"Everyone there was someone that I didn't know. However, I experienced an interaction between us [that was] quite similar to what I do in a real club situation. Without the presence of others, I think I would've found it much weirder to move like I did."

The combined results of the motion capture data and the questionnaire point to a coupling between the subjective feelings of pleasure and the measurable QoM. The dynamic changes in the dancers' movements, their experience of pleasure and intense desire to dance, correspond to the dynamic changes in the break routine. At the peak moment of the music - the drop-the motion capture data shows the group's highest QoM, and the self-reports indicate both a peak in the desire to dance and in the experienced pleasure.

\section{CONCLUDING REMARKS}

In this article we investigated the role of EDM tracks when people dance together in a club-like environment. The main focus has been on how a group of people relates to specific structural properties and sonic features in EDM.

The motion capture data shows a clear relation to the sonic features in the break routine. This is also supported by the questionnaire, which includes individual reports of intense pleasure at these peak moments in the track. Even though this study is limited in scope, the findings clearly support our hypothesis that there is a relationship between peak pleasurable experiences and specific structural properties of EDM, and that this relationship is expressed in people's movements. We also have qualitative evidence that continuous embodied pleasure sensations arose as the group was dancing, and that these sensations were also connected to the rhythmic framework and strong beat of the music.

The study supports our idea that clubbing may be seen as an intersubjectively embodied experience. The participants were in intersubjective agreement about which sonic features led to dynamic changes in their affective and embodied engagement - that is, the motion capture data indicated that they moved in similar ways to the same musical passages, while the questionnaire results reported the build-up and drop as particularly pleasurable and stimulating in terms of their desire to dance. Furthermore, according to the selfreports, the presence of others and their musical engagement are substantial factors in the shaping and reinforcement of one's own experience. This might suggest that the dancers have an intersubjectively embodied knowledge of how to respond to the structural properties of EDM, and that the break routine plays a key role in this co-shaping of behavior. Previous studies have underscored the role of rhythm in shared experiences of music (Becker, 2004; Blacking, 1992; Clayton, Sager, \& Will, 2004; Keil \& Feld, 2005; Lomax, 1982), and the removal and reintroduction of the rhythmic framework in the drop offers one explanation as to why this creates such intense pleasure and desire to dance.

\section{LIMITATIONS AND FURTHER RESEARCH}

One limitation in the current experimental setup was our inability to track the participants individually throughout the motion capture recording. This was due to the fact that the participants danced close together, often with their arms in the air, in a relatively small area, which led to the occlusion of motion capture markers. In future studies, we will explore the use of unique constellations of three markers on each person, so that people can be tracked individually. We will also try to use an accelerometer-based motion capture system, which has the added benefit of being usable in a real club setting. In this way it will also be possible to investigate different levels of synchronization between people in the group. In future research, we wish to include more participants, divided into several groups, to further investigate musical behavior at the group level in a club-like environment. In the present study, 16 people participated and danced simultaneously in one dance session to a fixed DJ mix. To reduce order effect, our next study will include several dance sessions in which the musical examples are presented to the groups in different successions. 


\section{ACKNOWLEDGMENTS}

The authors wish to thank Nicola Dibben and Rolf Inge Godøy for valuable feedback on the manuscript. They also thank Mari Romarheim Haugen for help during the motion capture recording. The authors are grateful for the thorough and constructive comments from the reviewers as well.

\section{NOTES}

[1] Correspondence can be addressed to Ragnhild Torvanger Solberg, ragnhild.t.solberg@uia.no.

[2] According to the EDM literature, breakdown and build-up are recognized terms. The passage following these passages is, however, described in multiple though related ways (see Solberg 2014 for an overview). In this article we identify this passage as the drop. This term relates to the passage's most noticeable features, namely the reintroduction of the bass and the bass drum, often referred to as "dropping the bass."

[3] The slightest body movement influences the measurement of physiological responses, and particularly the electro dermal activity, which is another reason why absolute sedentary listening has been preferred when measuring musical peak sensations.

[4] The original time points for the four excerpts presented in this article are as follows: track 1. "Joyride": 3:55-5:12; track 2. "Ladykiller”: 03:45-05:05 (breakdown: 03:51, build-up: 04:08, drop: 04:56); track 3. "Unlock Down”: 04:14-05:16; track 4. "Icarus”: 01:54-02:55 (breakdown: 02:02, build-up: 02:21, drop: 02:36).

\section{REFERENCES}

Becker, J. (2004). Deep listeners: Music, emotion, and trancing. Bloomington: Indiana University Press.

Berthoz, A., \& Jorland, G. (2004). L’Empathie. Paris: Jacob.

Blacking, J. (1992). The biology of music-making. In H. Myers (Ed.), Ethnomusicology: An introduction (pp. 301-314). London: Macmillan.

Blood, A. J., \& Zatorre, R. J. (2001). Intensely pleasurable responses to music correlate with activity in brain regions implicated in reward and emotion. Proceedings of the National Academy of Sciences of the United States of America, 98(20), 11818-11823. https://doi.org/10.1073/pnas.191355898

Burger, B., Saarikallio, S., Luck, G., Thompson, M. R., \& Toiviainen, P. (2013). Relationships between perceived emotions in music and music-induced movement. Music Perception: An Interdisciplinary Journal, 30(5), 517-533. https://doi.org/10.1525/mp.2013.30.5.517

Burger, B., Thompson, M. R., Luck, G., Saarikallio, S., \& Toiviainen, P. (2013). Influences of rhythm- and timbre-related musical features on characteristics of music-induced movement. Frontiers in Psychology, 4, 183. https://doi.org/10.3389/fpsyg.2013.00183

Burger, B., \& Toiviainen, P. (2015) The MoCap Toolbox-A Matlab toolbox for computational analysis of movement data. In R. Bresin (Ed.), Proceedings of the 10th Sound and Music Computing Conference 2013. Stockholm: KTH Royal Institute of Technology.

Butler, M. J. (2006). Unlocking the groove: Rhythm, meter, and musical design in electronic dance music. Bloomington: Indiana University Press. 
Camurri, A., Lagerlof, I., \& Volpe, G. (2003). Recognizing emotion from dance movement: Comparison of spectator recognition and automated techniques. International Journal of Human-Computer Studies, 59(12), 213-225. https://doi.org/10.1016/S1071-5819(03)00050-8

Camurri, A., Mazzarino, B., Ricchetti, M., Timmers, R., \& Volpe, G. (2003). Multimodal analysis of expressive gesture in music and dance performances. In A. Camurri \& G. Volpe (Eds.), Gesture-Based Communication in Human-Computer Interaction (vol. 2915, pp. 20-39). Berlin, Heidelberg: Springer. https://doi.org/10.1007/978-3-540-24598-8_3

Chen, J. L., Penhune, V. B., \& Zatorre, R. J. (2009). The role of auditory and premotor cortex in sensorimotor transformations. Annals of the New York Academy of Sciences, 11691(1), 15-34.

https://doi.org/10.1111/j.1749-6632.2009.04556.x

Clayton, M., Sager, R., \& Will, U. (2004). In time with the music: The concept of entrainment and its significance for ethnomusicology. European Meetings in Ethnomusicology, 11, 3-75.

Collin, M., \& Godfrey, J. (1997). Altered state: The story of ecstasy culture and acid house. London: Serpent's Tail.

Dahl, S., \& Friberg, A. (2003). Expressiveness of musician's body movements in performances on marimba. Gesture-Based Communication in Human-Computer Interaction, 2915, 479-486. In A. Camurri \& G. Volpe (Eds.), Gesture-Based Communication in Human-Computer Interaction (vol. 2915, pp. 479-486). Berlin/Heidelberg: Springer.

De Bruyn, L., Leman, M., Moelants, D., \& Demey, M. (2009). Does social interaction activate music listeners? In S. Ystad, R. Kronland-Martinet, \& K. Jensen (Eds.), Computer Music Modeling and Retrieval: Genesis of Meaning in Sound and Music (vol. 5493, pp. 93-106). Berlin/Heidelberg: Springer. https://doi.org/10.1007/978-3-642-02518-1_6

DeNora, T. (2000). Music in everyday life. Cambridge: Cambridge University Press. https://doi.org/10.1017/CBO9780511489433

Fikentscher, K. (2000). “You better work!”: Underground dance music in New York City. Hanover, New Hampshire: University Press of New England.

Garcia, L.-M. (2011). “Can you feel it, too?”: Intimacy and affect at electronic dance music events in Paris, Chicago, and Berlin. Ph.D. dissertation, University of Chicago.

Gebauer, L., Kringelbach, M. L., Vuust, P., Cohen, A. J., \& Stewart, L. (2012). Ever-changing cycles of musical pleasure: The role of dopamine and anticipation. Psychomusicology: Music, Mind, and Brain, 22(2), 152-167. https://doi.org/10.1037/a0031126

Godøy R. I., \& Leman, M. (2010). Musical gestures: Sound, movement, and meaning. New York: Routledge.

Gomez, P., \& Danuser, B. (2007). Relationships between musical structure and psychophysiological measures of emotion. Emotion, 7(2), 377-387. https://doi.org/10.1037/1528-3542.7.2.377

Grewe, O., Kopiez, R., \& Altenmüller, E. (2009). Chills as an indicator of individual emotional peaks. Annals of the New York Academy of Sciences, 1169, 351-354. https://doi.org/10.1111/j.1749-6632.2009.04783.x

Gritten A., \& King E. (2006). Music and gesture. Aldershot: Ashgate.

Gritten A., \& King E. (2011). New perspectives on music and gesture. Farnham: Ashgate.

Guhn, M., Hamm, A., \& Zentner, M. (2007). Physiological and musico-acoustic correlates of the chill response. Music Perception: An Interdisciplinary Journal, 24(5), 472-483. 
https://doi.org/10.1525/mp.2007.24.5.473

Haga, E. (2008). Correspondences between music and body movement. Ph.D. dissertation, University of Oslo.

Intersubjective. (2015a). In Collins English Dictionary. Retrieved from http://www.collinsdictionary.com/ dictionary/english/intersubjective.

Intersubjective. (2015b). In Oxford English Dictionary. Retrieved from http://www.oed.com/view/Entry/ 98368?redirectedFrom=intersubjective\&

Jackson, P. (2004). Inside clubbing: Sensual experiments in the art of being human. Oxford: Berg.

Janata, P., Tomic, S. T., \& Haberman, J. M. (2012). Sensorimotor coupling in music and the psychology of the groove. Journal of Experimental Psychology: General, 141, 54-75. https://doi.org/10.1037/a0024208

Juslin, P. N., \& Västfjäll, D. (2008). Emotional responses to music: The need to consider underlying mechanisms. Behavioral and Brain Sciences, 31(5), 559-575. https://doi.org/10.1017/S0140525X08005293

Keil, C., \& Feld, S. (2005). Music grooves: Essays and dialogues (2nd ed.). Tucson, Arizona: Fenestra.

Keitz, M., Martin-Soelch, C., \& Leenders, K. L. (2003). Reward processing in the brain: A prerequisite for movement preparation. Neural Plasticity, 10(1-2), 121-128. https://doi.org/10.1155/NP.2003.121

Leman, M. (2008). Embodied music cognition and mediation technology. Cambridge, Massachusetts: MIT Press.

Leman, M., \& Naveda, L. (2010). Basic gestures as spatiotemporal reference frames for repetitive dance/music patterns in samba and Charleston. Music Perception: An Interdisciplinary Journal, 28(1), 7191. https://doi.org/10.1525/mp.2010.28.1.71

Lomax, A. (1982). The cross-cultural variation of rhythmic style. In M. Davis (Ed.), Interaction Rhythms: Periodicity in Communicative Behaviour (pp. 149-174). New York: Human Sciences Press.

MacDougall, H. G., \& Moore, S. T. (2005). Marching to the beat of the same drummer: The spontaneous tempo of human locomotion. Journal of Applied Physiology, 99, 1164-1173.

https://doi.org/10.1152/japplphysiol.00138.2005

Malbon, B. (1999). Clubbing: Dancing, ecstasy and vitality. London: Routledge.

McNeill, W. H. (1995). Keeping together in time: Dance and drill in human history. Cambridge, Massachusetts: Harvard University Press.

Moelants, D. (2002). Preferred tempo reconsidered. In C. Stevens, D. Burnham, G. McPherson, E. Schubert, \& J. Renwick (Eds.), Proceedings of the 7th International Conference on Music Perception and Cognition, Sydney, 2002 (pp. 580-583). Adelaide: Causal Productions.

Moelants, D. (2008, August). Hype vs. natural tempo: A long-term study of dance music tempi. Paper presented at the 10th International Conference on Music Perception and Cognition, Japan. Retrieved from http://hdl.handle.net/1854/ LU-438283

Overy, K., \& Molnar-Szakacs, I. (2009). Being together in time: Musical experience and the mirror neuron system. Music Perception: An Interdisciplinary Journal, 26(5), 489-504.

https://doi.org/10.1525/mp.2009.26.5.489 
Panksepp, J. (1995). The emotional sources of "chills" induced by music. Music Perception: An Interdisciplinary Journal, 13(2), 171-207. https://doi.org/10.2307/40285693

Repp, B. (2005). Sensorimotor synchronization: A review of the tapping literature. Psychonomic Bulletin \& Review, 12(6), 969-992. https://doi.org/10.3758/BF03206433

Repp, B., \& Su, Y.-H. (2013). Sensorimotor synchronization: A review of recent research (2006-2012). Psychonomic Bulletin \& Review, 20(3), 403-452. https://doi.org/10.3758/s13423-012-0371-2

Reynolds, S. (1998). Energy flash: A journey through rave music and dance culture. London: Picador.

Rickard, N. S. (2004). Intense emotional responses to music: A test of the psychological arousal hypothesis. Psychology of Music, 32(4), 371-388. https://doi.org/10.1177/0305735604046096

Rietveld, H. C. (1998). This is our house: House music, cultural spaces and technologies. Aldershot: Ashgate.

Salimpoor, V., Benovoy, M., Larcher, K., Dagher, A., \& Zatorre, R. (2011). Anatomically distinct dopamine release during anticipation and experience of peak emotion to music. Nature Neuroscience, 14(2), 257-355. https://doi.org/10.1038/nn.2726

Solberg, R. T. (2014). "Waiting for the bass to drop”: Correlations between intense emotional experiences and production techniques in build-up and drop sections of electronic dance music. Dancecult, 6(1), 61-82. https://doi.org/10.12801/1947-5403.2014.06.01.04

St. John, G. (2004). Rave culture and religion. London: Routledge.

Stupacher, J., Hove, M., Novembre, G., Schutz-Bosbach, S., \& Keller, P. (2013). Musical groove modulates motor cortex excitability: A TMS investigation. Brain Cognition, 82(2), 127-136.

https://doi.org/10.1016/j.bandc.2013.03.003

Thornton, S. (1995). Club cultures: Music, media and subcultural capital. Cambridge: Polity Press.

Toiviainen, P., Luck, G., \& Thompson, M. R. (2010). Embodied meter: Hierarchical eigenmodes in music-induced movement. Music Perception: An Interdisciplinary Journal, 28(1), 59-70.

https://doi.org/10.1525/mp.2010.28.1.59

Van Dyck, E., Maes, P., Hargreaves, J., Lesaffre, M., \& Leman, M. (2013). Expressing induced emotions through free dance movement. Journal of Nonverbal Behavior, 37(3), 175-190.

https://doi.org/10.1007/s10919-013-0153-1

Van Dyck, E., Moelants, D., Demey, M., Deweppe, A., Coussement, P., \& Leman, M. (2013). The impact of the bass drum on human dance movement. Music Perception: An Interdisciplinary Journal, 30(4), 349-359. https://doi.org/10.1525/mp.2013.30.4.349

Wanderley M., \& Battier M. (2000). Trends in gestural control of music. Paris: IRCAM—Centre Pompidou.

Witek, M. A. G. (2013). “... and I feel good!” The relationship between body movement, pleasure and groove in music. Ph.D. dissertation, University of Oxford.

Witek, M. A. G, Clarke, E. F., Wallentin, M., Kringelbach, M. L., \& Vuust, P. (2014). Syncopation, body movement and pleasure in groove music. PLOS ONE, 9(4), 1-12.

https://doi.org/10.1371/journal.pone.0094446

Zeiner-Henriksen, H. T. (2010). The "PoumTchak" pattern: Correspondences between rhythm, sound, and movement in electronic dance music. Ph.D. dissertation, University of Oslo. 
Zentner, M., Eerola, T., \& Purves, D. (2010). Rhythmic engagement with music in infancy. Proceedings of the National Academy of Sciences of the United States of America, 107(13), 5768-5773.

https://doi.org/10.1073/pnas.1000121107

\section{DISCOGRAPHY}

Madeon. (2012). “Icarus (Extended Mix).” On Icarus [Single]. France: Popcultur. URL: https://www.youtube.com/watch?v=EUC17C-DgDs

NUAGE. (2014). “Unlock Down (Original Mix).” On My Patience [EP]. Russia: Electronica Records. URL: https://www.youtube.com/watch?v=r1sAGU-kQ3Q

Rhode \& Brown, Schegg. (2013). “Joyride.” On Joyride [EP]. Germany: Toy Tonics. URL: https://www.youtube.com/watch?v=dPLgnJ9R_4Y

Vanilla Ace. (2014). “Ladykiller (Original Mix).” On Ladykiller [Single]. UK: Erase Records. URL: https://www.youtube.com/watch?v=itaH-YrAVa8 